\title{
Loanwords in Japanese Language: A Linguistic Perspective
}

\author{
Yi-nan $\mathrm{Li}^{1}$, Yang Gao ${ }^{2}$ \\ ${ }^{1)}$ Department of Japanese, Dalian Neusoft University of Information, Dalian, Liaoning, China \\ ${ }^{2)}$ School of Teaching, Learning and Curriculum Studies, Kent State University, Kent, Ohio, the USA
}

\begin{abstract}
From a linguistic perspective, the present paper discusses effects of loanwords in Japanese to its language development. It first introduces definition of loanwords and researchers' debate on Chinese as loanwords in Japanese. Then, it briefly discusses sources and origins of loanwords in Japanese. The major part of the present paper focuses on how loanwords in Japanese influence its language development through a linguistic perspective, which is further developed from linguistic branches in phonetics, phonology, lexicology, morphology and semantics. The paper ends up with authors' suggestions on future studies related to the topic.
\end{abstract}

Keywords - loanwords, Japanese language, a linguistic perspective.

\section{从语言学视角浅谈日语中的外来语}

\author{
李义楠 $^{1}$ 高洋 $^{2}$ \\ 1) 大连东软信息学院日语系, 大连, 辽宁, 中国 \\ 2) 肯特州立大学教学课程研究学院, 肯特, 俄亥俄州, 美国
}

\begin{abstract}
摘 要 本文从语言学角度谈论了日语中的外来语对其语言发展的影响。本文首先介绍了外来语的定义, 以及学者们对汉语在日 语外来语的归属问题的争论现象。本文接下来浅谈了日语外来语的起源和来源。本文的主要部分则围绕着如何从传统语言学的细分分 支, 即语音学, 音系学, 词汇学, 形态学以及语义学各方面, 探讨日语中的外来语对其语言的发展影响。文章结尾处, 作者们对此题 目未来研究方向给予了建议。
\end{abstract}

关键词 外来语, 日语, 语言学视角

\section{1. 日语中的外来语}

\section{1 外来语定义}

所谓外来语, 顾名思义, 就是指从外来国家舶来的语 言。人们又常将其称为借入语, 归化语。日语中的外来语 主要是指从其他国家的语言中借用一部分语言符号, 绝大 多数情况下指的是词汇, 先将其应用于日语中, 随后又将 其完全融入吸收进日语体系, 将其本国语化的产物。

\section{2 汉语在日语中的归属问题}

既然外来语是指从外来国家借入的语言, 那么汉语是 否也算做日语中外来语呢? 对此问题, 不同语言学者有着 不同的看法。从广义上讲, 汉语应该算作日语中的外来语, 因为根据外来语的定义, 汉语是从中国传入日本的语言,
而狭义而言, 许多研究认为汉语不应该算作日语中的外来 语, 其根据为: 1) 所谓外来语, 其特点之一在于 “本族语 内部各语言或方言间的相互借用, 不属于外来语范畴, 外来语必须以外国语和本国语的共存为先行条件, 必须是 二者相结合的产物, 或者说是二者统一的产物”(林坡, 2008, p. 180)。而众所周知汉语是日语重要的组成部分, 或者说 日语是汉语的同族语言, 隶属于汉藏语系语言, 那么汉语 就不应看作是日语的外来语；2）现行意义上的外来语一般 被认为是以西方传教士初访日本的 16 世纪中叶为界 (赵春 娥, 2003), 而时至此时 (16 世界中叶), 汉语早已成为日 语的重要载体, 并已沉淀了悠久的文字文化历史, 日本人 对汉语已不存在舶来品的感觉, 早已纳入其本国的文化之 中。马克思主义哲学认为, 真理是相对的, 所以在汉语与 日语外来语的关系问题上, 笔者认为可以视研究者具体需 
求而定, 在学术的研究领域, 值得推崇 “百家争鸣, 百花 齐放” 的方针, 有助于学术研究的进展 (肖前, 1994)。

\section{3 日语外来语的形成原因及历史传入过程}

从宏观角度来说, 日语中的外来语的产生同样基于此 原理, 为了解决因新鲜事物的传入而在解释描述方面本国 语言又匮乏的问题, 日语中引用了大量的外来语, 而经过 长期的使用过程, 这些外来语被本国语同化, 纳入了本国 语体系中。诚然, 从微观角度而言, 日语中的外来语形成 还存在来自社会交际需要, 日常表达需要等等因素, 如在 国际贸易往来中的商务谈判方面, 日常生活中的委婉表达 方面, 人们随处可见外来语的使用情况。

如果将汉语看作是日语中的外来语, 则日语中外来语 的传入过程大致可以分为三个阶段: 1. 五世纪时, 中国的 汉语传入日本, 日本人至此开始使用汉语为日语中事物开 始命名: 公元 645 年的大化改新至 894 年废除遣唐使的二 百余年间, 中国文化被大量引入日本并迅速繁兴, 此为日 语外来语发展的第一阶段; 2. 东方文化的借鉴并不能完全 满足日语的发展, 从幕府末期和明治维新开始, 直至二战 结束, 西方文化逐渐传入日本, 部分新鲜事物及其名词解 被日语吸收囊括, 供应日语的发展, 此为日语外来语发展 的第二阶段; 3. 而从二战后至今, 西方各国语言词汇继续 传入日本, 日本外来语词汇迅速增加, 此为日语外来语发 展的第三阶段。若不考虑汉语作为日语外来语的因素, 则 最早的日语外来语则追溯到十六世纪, 出现在葡萄牙人登 陆日本进行贸易和传教活动以后, 西欧大陆各个国家陆续 将其本国语言词汇带入日本, 促进了日语外来语的发展。

\section{2. 从语言学视角论述外来语对日语的影响}

外来语的大量涌入, 对日语语言本身方方面面产生了 极大的影响, 从而对日语的发展起到了积极的推动作用。 从理论语言学的视角出发, 外来语对日语的影响可以体现 在如下几个方面:

\section{1 语音学 (PHONETICS)}

由于日语中音节和音素(PHONEME)较少, 故在外来语 大量传入之后, 出现了无法拼读的现象。为解决此问题, 1991 年, 日本内阁颁布了《外来语的标记》, 规定了用于 标记外来语的音节由原来的 103 个标准音节扩展为 136 个, 增加了 33 个(ッァ、ファ、クア、グァ、ヴァ、ティ、フ イ、ディ、ウィ、クィ、ツィ、ヴィ、トゥ、ドゥ、ヴ、 ヴェ、イエ、ウェ、クェ、シェ、チェ、ツェ、フェ、ジ エ、ツォ、フォ、ウォ、クォ、ヴォ、テュ、デュ、フュ、 ヴュ)。《外来语的标记》的实施为日语中外来语的发音完
善了发展空间, 拓宽了外来语发音的渠道。

\section{2 音系学 (PHONOLOGY)}

日语中外来语的引进, 同样影响了日语中一些发音规 则(RULES): 如促音规则, 这主要体现在外来语的传入使 促音使用规则的范围有所扩大: 传统的促音规则规定, 除 了日语方言中的促音以外, 促音一般用于 (かさたぱ 4 行) 之前。外来语传入之后, 促音规则出现了相应的调整, 即: 但凡外来语原语为闭音节, 其元音为短元音, 而尾音为爆

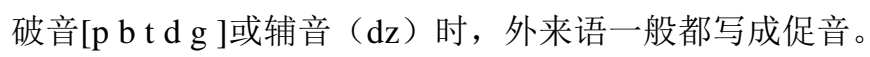
如ペット (pet)、レッグ (leg)、ガッッ (guts)。

\section{3 词汇学 (LEXICOLOGY)}

冊庸置疑, 人们谈到日语外来语时, 首先想到的层面 非外来语词汇莫属; 甚言之, 我们可以将现行人们提到的 “日语外来语” 从狭义角度理解为日语外来语词汇。所以 日语外来语中引用的词汇无疑对日语的发展起到了最大的 推动作用, 其主要体现在以下两个方面:

1) 词素量的扩大(LEXEME): 外来语词汇的大量涌入 为日语语言系统增加了更多的词素, 积极地丰富了日语词 汇, 这些外来语词汇覆盖领域广阔, 囊括了经济, 政治, 科技，体育等各个方面。

2) 构词法的增加(WORD-FORMATION): 从语言学中 词汇学和形态学的角度出发, 日语中外来语的大量涌入对 日语混合构词法空间提供了上升的阶梯:

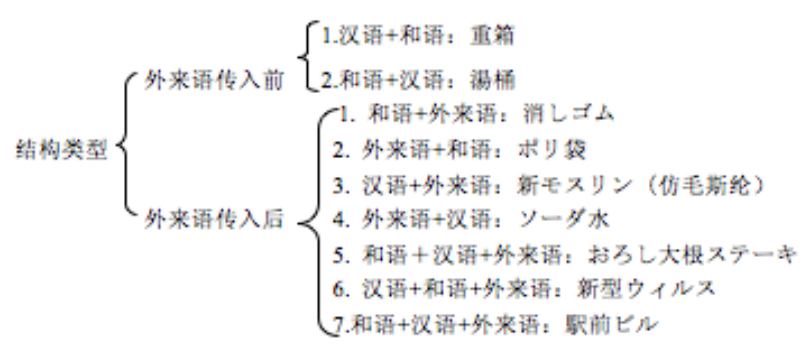

图 1 外来语的传入前后对日语构词法的影响

如图所示, 较外来语传入前的 “汉语加和语”, “和语加 汉语”两种单一结构类型相比, 外来语传入后的日语构词体 系中又增加了 “和语加外来语”, “外来语加和语”, “汉 语加外来语”, “外来语加汉语”, “汉语加和语加外来语”, “和语加汉语加外来语”等多种构词模式, 为扩大日语词汇 量提供了巨大辅助作用。

\section{4 形态学 (MORHOLOGY)}

日语外来语引入后对日语的影响从形态学角度来思 
考, 主要体现在日语标记方面, 这与上述的音系学及词汇 学领域有部分的内容覆盖现象, 其主要体现在: 1) 标音符 (DIACRITICS), 即日语中的假名的数量扩大, 由 103 个假 名扩大到 133 个; 2) 构词法, 由两种词汇结构类型扩展 为七种。

\section{5 语义学 (SEMANTICS)}

语义学是研究语言意义的学科, 任何一个事物本身都 由其特定的意义。外来语作为一种客观存在实体, 必然拥 有其本身的内涵, 而这些意义的引进势必为日语的文化积 累了厚重的底蕴。一些西欧国家的先进技术被不断引进日 本, 对日本民众的生活带来了丰富的内容; 而外来语的出 现对日本人民理解、消化, 及吸收这些新鲜事物和先进技 术的意义上起到了积极有力的推动作用。

\section{3. 结语}

本文从理论语言学的角度梳理了日语中外来语对日语 形成发展的影响。作为日语体系构成的重要部分, 日语中
的外来语值得广大语言学者及教师的密切关注。未来的相 关研究可从应用语言学的角度, 如语用学, 二语习得, 跨 文化等方面继续梳理及探讨外来语对日语发展的影响。此 外, 相对于理论研究, 有关于此课题的实证研究更应该受 到语言学者, 研究者及教师的足够重视。

\section{参考文献(References)}

[1] P. Lin, "On the loanwords in Japanese," Journal of Heilongjiang Science and Technology Information, no. 17, p. 180, July 2008.

[2] C. Zhao, "On Japanese loanwords", Journal of Qiqihar University (Phi \& Soc Sci), no. 3, pp. 132-133, May 2003.

[3] Q. Xiao, "Marxism Philosophy", Chinese People's University Press, 1994.

[4] Y. Yang, "On the origins of Japanese loanwords," Journal of Heilongjiang College of Education, vol. 36, no. 3, pp. 94-96, July 2008. 